


\title{
The 100th of the world's worst invasive alien species
}

\author{
Gloria M. Luque · Céline Bellard · Cleo Bertelsmeier . \\ Elsa Bonnaud $\cdot$ Piero Genovesi $\cdot$ Daniel Simberloff $\cdot$ Franck \\ Courchamp
}

\begin{abstract}
Biological invasions are among the greatest threats to global biodiversity, but in contrast to most other global threats, they suffer from specific communication issues. Our paper presents the first new addition to the widely cited IUCN list of " 100 of the world's worst invasive species", a list created a decade ago in response to these communication issues. We briefly present this list, the recent removal of one species from that list, and the rationale to include a novel, 100th species to replace it. The new species of this list, giant salvinia (Salvinia molesta), was chosen by the community of invasion biologists (over 650 experts from over 60 countries). This new addition to the list will draw public attention to the damage caused by invasive alien species and it will help stimulate the necessary discussion of this critical issue in science and policy circles.
\end{abstract}

G. M. Luque (\&) ·C. Bellard ·C. Bertelsmeier ·

E. Bonnaud $\cdot$ F. Courchamp

Ecologie, Systématique et Evolution, UMR CNRS 8079,

Univ Paris-Sud, Orsay, France

e-mail: gloria.luque@u-psud.fr

P. Genovesi

Chair IUCN SSC Invasive Species Specialist Group, Institute for Environmental Protection and Research,

Rome, Italy

D. Simberloff

Department of Ecology and Evolutionary Biology,

University of Tennessee, Knoxville, TN, USA

\section{Introduction}

Although invasive alien species (IAS) are regarded as the second largest threat to biodiversity worldwide (after habitat loss; Clavero and Garcia-Berthou 2005; Simberloff et al. 2013), and their economic cost probably exceeds US $\$ 300$ billion per year worldwide (Pimentel et al. 2000; Genovesi 2011), the increased adoption of specific legislation by many nations has had limited effect on the rate of new introductions (McGeoch et al. 2010). In Europe for example, over twelve thousand alien species have been documented (Hulme et al. 2009), with an increase of over $76 \%$ in alien species over the last 40 years (Butchart et al. 2010). Despite the progress of a large, dedicated community of researchers and managers worldwide, management successes against invasive alien species are still outnumbered by new introductions. Obviously, our improved knowledge about the harm they can cause, better management procedures to prevent new introductions, and more efficient eradication protocols remain insufficient (Genovesi 2011). New introductions in fact parallel the increase in intercontinental transportation of goods and people, which allows species to overcome long distances and geographical barriers. In addition, owing to the frequent time lags between introduction and observed impact, 
the full extent of current invasions will not be recognized for several decades (Essl et al. 2011). Biological invasions might also increase further in the future because of global environmental changes, in particular climate and land use changes (Walther et al. 2009; Bellard et al. 2013).

\section{Need to communicate about IAS}

Although the current biodiversity crisis has generated concern both among the general public and with decision makers, IAS have proven difficult to deal with. In particular, awareness of the threat represented by biological invasions is impeded by the lack of a clear, identifiable target, owing to the tremendously high number of IAS and the even higher number of species that have the potential to become invasive. Consequently, not only are the programs aiming to limit the impacts of IAS still insufficient, but also the very awareness of the threats caused by IAS remains diffuse. Given these difficulties, invasion biologists have recognized that the need to communicate more efficiently and authoritatively is a key to success. Yet, among so many species of microorganisms, plants, invertebrates, and vertebrates, marine, freshwater, and terrestrial alike, communication efforts are often diluted, whereas specific targets are better at eliciting attention from the public and decision makers. In 1999, the International Union for the Conservation of Nature (IUCN), through its Invasive Species Specialist Group (ISSG) of the Species Survival Commission, set up a remarkable communication tool to address this issue: a list of 100 high-profile invasive species, all known to be tremendously harmful and prompting a dire need for conservation action. Subsequently, the list of " 100 of the world's worst invasive alien species" has boosted global awareness.

\section{0 of the world's worst invasive species}

This list of 100 species was derived according to two criteria: their serious impact on biodiversity and/or on human activities, and their potential to illustrate important issues surrounding biological invasions (Lowe et al. 2004). To ensure the inclusion of a wide variety of examples, only one species from each genus was selected. As a result, the 100 species belong to many taxonomic groups, from microorganisms to plants and vertebrates (Fig. 1). They come from all continents and have impacts on local biodiversity and ecosystem functioning, and on agriculture, forestry, or aquaculture; they affect landscape or real estate values and constitute health hazards, as allergens or as disease vectors. Two points were relentlessly emphasized as this list was promoted. First, absence from the list does not imply that a species poses a lesser threat. Second, these are not the 100 worst invaders, but 100 among the worst. Evidently, it would be very hard to rank diverse species with such varied impacts. The aim of this list was to highlight the importance of invasive alien species, by emphasizing those that belong to the list, but avoiding at all cost downplaying the importance of the thousands of species not on this list.

This list has been a tremendous success in terms of communication, with over 1,000 citations in the scientific literature and a number of similar lists promulgated for different regions or environments (e.g., Streftaris and Zenetos 2006; Vila` et al. 2009). Among the achievements is the successful global eradication of the rinderpest virus, a mere decade after the list was constructed, which reduced it to 99 species (World Organisation for Animal Health 2011). Subsequently, it was decided to replace the eliminated species, to keep the list at 100, rather than working to reduce it progressively. This course of action has the double advantage of highlighting yet another major invader and insisting on the fact that species that are not on the IUCN 100 list can nonetheless be among the worst invaders worldwide. On the contrary, constantly reducing the list would have given the misleading impression that IAS were getting gradually fewer.

The selection of the 100th species

To this effect, it was decided to enlist the community of invasion biologists in selecting the new, 100th IAS for the list. As it would be difficult to get a meaningful consensus from a pool of tens of thousands of IAS species, we first selected a reasonable number of candidates among which the community was invited to choose. Following the same thinking behind the development of the original list, this approach was not meant to be an accurate and objective selection of the worst invaders, but rather a rational selection of some 


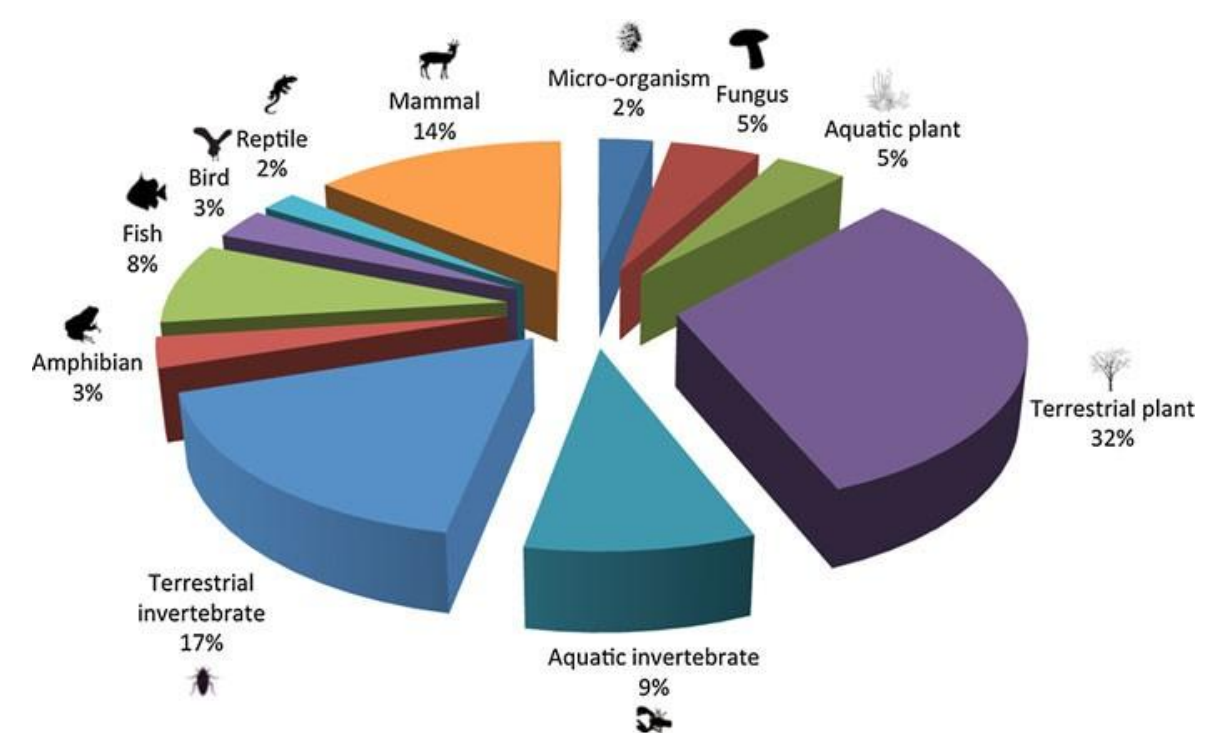

Fig. 1 Taxonomic representation of 100 of the world's worst alien invasive species

of the worst, as it is difficult to classify objectively and quantitatively one species as worse than another. We thus amassed invasive alien species inventories/ checklists from 16 global and national databases, including the ISSG Global Invasive Species Database (GISD), CABI Invasive Species Compendium (ISC) and DAISIE (Delivering Alien Invasive Species Inventories for Europe), and selected over 10,000 IAS that we ranked based on the number of times they were listed. We then accounted for emerging threats, i.e., species that are not yet widespread but that are known to have major impacts and/or a high spread rate, so that they would rise in the ranking. We selected the first 50 species and assigned to each of them a score of (1) spread: the number of continents already invaded and (2) impact: ecological, economic and/or health. We finally eliminated the species in genera that were already represented in the 100-list, as well as those that had a strong positive value (cultural or economic). We then selected the 10 species with the highest sum of scores. These 10 species were six aquatic and four terrestrial organisms, five plants and five animals. They came from South and North America, Asia, Europe and Oceania and had strong ecological, economic and/or health impacts. They included organisms that are invasive throughout the world, such as the American waterweed Elodea canadensis, but also still localized but very fast spreading organisms, such as the lionfish Pterois volitans, or species with very high local impact, such as the Burmese python Python molurus bivittatus. The address of a dedicated web site (Courchamp 2013) was distributed via various networks to the invasion biology community throughout a period of 3 months. The site included a description of the selection protocol, a short presentation of the 10 candidates and an explanation on how to vote online for the latest and 100th representative of the IUCN "100 of the worst' ' list. We used the Condorcet Vote, a procedure that selects the candidate (here a species) that would win by majority rule in all pairings against the other candidates (Courchamp 2013). It requires only one round of voting.

A total of 652 experts from 63 countries voted, and they selected giant salvinia, Salvinia molesta, as the 100th species to join the IUCN list of " 100 of the world's worst invasive alien species". It is a freefloating aquatic fern (Fig. 2) native to southeastern Brazil, first observed outside its native range in 1939. It has since spread widely throughout the tropics and subtropics across the world and is currently found in 31 countries on 4 continents (Fig. 2). This plant is moved in part by the trade in ornamental plants for fish tanks and ponds. The presence of giant salvinia is prominent in slow-moving, quiet freshwater systems. Its fast growth rate, under optimal conditions, enables this plant to double its abundance in only a few days. It forms $10-20 \mathrm{~cm}$ thick floating mats (Fig. 2) that prevent light penetration of the water column, reducing oxygen content and degrading water quality for 

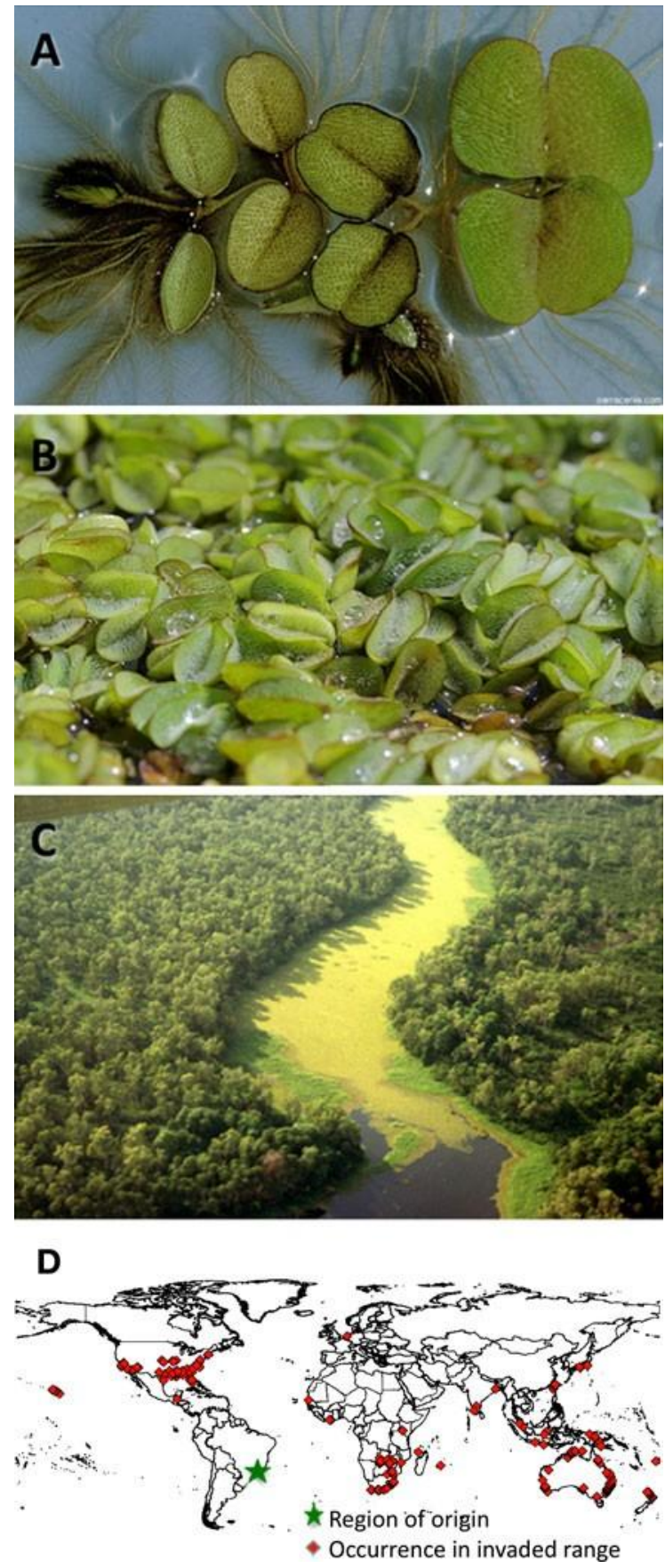

Fig. 2 a Close up of $S$. molesta, b free-floating aquatic group of salvinia, c floating mats of salvinia in Australia, d records of salvinia worldwide collected from a variety of databases including GBIF (http://data.gbif.org), CABI (www.cabi.org/ isc), and IOBIS (http://www.iobis.org/)

aquatic organisms, drastically damaging these ecosystems over large areas (Fig. 2). In addition, dense mats of salvinia can impede water-based transport, reduce water quality, impair aesthetic values, clog irrigation and power generation intakes, and harm local fisheries (Julien et al. 2002). Maintaining giant salvinia at low levels is generally attempted by the use of herbicides, which are notoriously costly. Biological control programs can achieve local successes but have not controlled salvinia in other areas, nor prevented its spread (Room et al. 1984; Julien et al. 2002).

Although salvinia definitely deserves its place in the list, other species among the 10 candidates, and beyond, could have been selected instead. The new status of salvinia does not make it suddenly more invasive, more damaging or more rapidly spreading. Nor has the need to remove it from invaded areas, or to prevent new introductions, suddenly become more critical. However, a listing in this very special catalogue will surely grant this species some extra attention, which will help impede its establishment and spread from now on. Invasion biologists also expect and hope that this new addition to the list will draw public attention to the damage caused by IAS in general. The IUCN list of " 100 of the world's worst invasive alien species" is a potent communication tool. One of the expectations of the invasion biology community when building this list was, oddly, that it would help them to remove species from it, as often as possible. Control of alien invasive species, even eradication when possible, is crucial to preserve biodiversity and lower costs for human societies. However, although reactive programs are required, they remain far more expensive than proactive programs (Kaiser and Burnett 2010). Prevention, early detection, and rapid response are the three pillars of success, and this rest on effective communication.

\section{References}

Bellard C, Thuiller W, Leroy B, Genovesi P, Bakkenes M, Courchamp F (2013) Will climate change promote future invasions? Glob Change Biol

Butchart SHM, Walpole M, Collen B, van Strien A, Scharlemann JPW, Almond REA, Baillie JEM, Bomhard B et al (2010) Global biodiversity: indicators of recent declines. Science 328:1164-1168

Clavero M, Garcia-Berthou E (2005) Invasive species are a leading cause of animal extinctions. Trends Ecol Evol 20:110

Courchamp F (2013) Internet survey for the selection of the 100th www.ese.u-psud.fr/epc/conservation/pages/the100th/ index.html 
Essl F, Dullinger S, Rabitsch W, Hulme PE, Huber K, Jarosık V, Kleinbauer I, Krausmann F et al (2011) Socioeconomic legacy yields an invasion debt. Proc Natl Acad Sci USA 108:203-207

Genovesi P (2011) Are we turning the tide? Eradications in times of crisis: how the global community is responding to biological invasions. Island Invasive Erad Manag 5-8

Hulme PE et al (2009) Delivering alien invasive species inventories for Europe (DAISIE) Handbook of alien species in Europe. Springer, New York

Julien M, Center T, Tipping P (2002) Floating fern (Salvinia). In: van Driesche R, Blossey B, Hoddle M, Lyon S, Reardon $\mathrm{R}$ (eds) Biological control of invasive plants in the Eastern United States (FHTET-2002-2004). United States Department of Agriculture Forest Service, Washington, pp 17-32

Kaiser BA, Burnett KM (2010) Spatial economic analysis of early detection and rapid response strategies for an invasive species. Resour Energy Econ 32:566-585

Lowe S, Browne M, Boudjelas S, De Poorter M (2004) 100 of the World's worst invasive alien species. A selection from the Global Invasive Species Database. The Invasive Species Specialist Group (ISSG) a specialist group of the Species Survival Commission (SSC) of the World Conservation Union (IUCN)

McGeoch MA, Butchart SHM, Spear D, Marais E, Kleynhans EJ, Symes A, Chanson J, Hoffmann M (2010) Global indicators of biological invasion: species numbers, biodiversity impact and policy responses. Divers Distrib 16:95-108

Pimentel LachL, Zuniga R, Morrison D (2000) Environmental and economic costs of nonindigenous species in the United States. Bioscience 50:53-65

Room PM, Forno IW, Taylor MFJ (1984) Establishment in Australia of two insects for biological control of the floating weed Salvinia molesta. Bull Entomol Res 74:505-516

Simberloff D, Martin JL, Genovesi P, Maris V, Wardle DA, Aronson J, Courchamp F, Galil B et al (2013) Impacts of biological invasions: what's what and the way forward. Trends Ecol Evol 28:58-66

Streftaris N, Zenetos A (2006) Alien marine species in the mediterranean-the 100 'worst invasives' and their impact. Mediterr Marine Sci 7:87-118

Vila` M, Basnou C, Gollasch S, Josefsson M, Pergl J, Scalera R (2009) One hundred of the most invasive alien species in Europe. In: Handbook of alien species in Europe. Springer, Netherlands, pp 265-268

Walther GR, Roques A, Hulme PE, Sykes MT, Pysek P, Kuhn I, Zobel M, Bacher S et al (2009) Alien species in a warmer world: risks and opportunities. Trends Ecol Evol 24:686693

World Organisation for Animal Health (2011) Resolution no. 18. Declaration of global eradication of rinderpest and implementation of follow-up measures to maintain world freedom from rinderpest. The Organisation, Paris 